\title{
Clinical study on ruminal disorders in cow
}

Galbat S. A.

Department of Animal Medicine, Faculty of Vet. Med. New valley University, Egypt

Received: 05 Sept. 2020 / Accepted 15 Oct. 2020 / Publication date: 30 Oct. 2020

\begin{abstract}
Thirty five adult native breed Egyptian cattle were introduced to a privet clinic suffering from ruminal disorders. The animals were divided into three groups, based on clinical signs and ruminal ph. The number of diseased cases with severe ruminal acidosis was fifteen, while the animals suffering from simple indigestion were twelve and those with ruminal tympany were eight. In addition, five clinically adult caws were used as control. Most cases with ruminal indigestion showed partial or complete anorexia, loss of body condition, abdominal pain, cessation of rumination and abdominal distension. Such signs differ according to the disease condition. Ruminal samples and blood samples were collected from all animals and transferred to the laboratory for biophysical and hematological analyses. All samples collected from diseased cases showed changes in the rumen microbial activity. All cases with ruminal dysfunction showed reduction in values and percentages of total and differential protozoal count. Hematological parameters Such as hemoglobin, packed cell volume (PCV), erythrocyte, Leucocyte and differential counts were performed. A significant increase in pulse and respiratory rates and significant decrease in rumen motility was observed in both acidosis and tympany. Rumen $\mathrm{pH}$ decreased significantly in acidosis and simple indigestion and increase in ruminal tympany. In rumen liquor the protozoal count, motility and activities were significantly reduced. Increased PCV was seen in both acidosis and tympany.
\end{abstract}

Keywords: Clinical study, ruminal disorders, cow.

\section{Introduction}

Ruminal disorders are significant critical problem to ruminant, Increases the morbidity and mortality of animals, markedly reduces weight gains in the feedlot, and complicates drought feeding strategies for sheep and cattle, it may be the most significant health disorder of ruminants fed on highquality pastures and grain

The most common rumen dysfunction is usually defined as indigestion. The term indigestion is a general term for a group of diseases that describe mainly the reticulorminal dysfunction (Radostits et al., 2000).

Rumen disorders had a great clinical interest because of the high morbidity and the great losses in both production and costs of treatment of affected ruminants. From the economic point of view, forestomach diseases result in great losses of the producers through deaths of animals, wasted feed, delayed marketing of the recovered animals, incomplete utilizing of disease provoking food and extra labor costs of preventive and therapeutic measures (Kimberlin, 1988).

The common etiological factors leading to indigestion were over feeding. Sudden change of diet, excess of indigestible e roughages, seasonal influences and inadequate supply of wholesome drinking water, resulting in Change of $\mathrm{pH}$ of rumen liquor either too acidic or too Alkaline (Bhaskar and Gautam, 1976). High quantities of urea intake resulted in high alkalinity of rumen contents ( $\mathrm{pH} 8.0$ to 8.5 ) with atony (Nichols, 1957). 1959).

Alkaline indigestion was caused due to ingestion of excessive protein diet (Annison and Lewis

Also feeding exclusively paddy straw for 4 weeks resulted in alkaline indigestion in cattle (Misra and Tripathy 1963). Many cases of indigestion in ruminants were due to an inadequacy of rumen microorganisms (Hoflund 1951). When cattle were fed exclusively on paddy straw, the protozoan number and their motility was very poor, though slight improvement in their concentration and motility could be observed just after feeding (Misra and Tripathy 1963). The rumen microorganisms were anaerobic and adapted to live at a temperature of $39^{\prime \prime}$ to $40^{\circ} \mathrm{C}$ with a $\mathrm{pH}$ ranging from 5.5 to 7.0 (Hungate 1966).

Corresponding Author: Galbat S. A., Department of Animal Medicine, Faculty of Vet. Med. New valley University, Egypt. E-mail: salahgalbat@yahoo.com 
Foreign body impaction has been recorded in bovine and ovine specifically in developing countries due to lack of recycling industries wastes (Vanitha et al., 2010).

Acidosis is a pathological condition associated with the accumulation of acid or depletion of alkaline reserves in blood and body tissues, and characterized by increased hydrogen ion concentrations (Blood and Studdert 1988). Ruminal acidosis refers to a series of conditions that reflect a decrease in $\mathrm{pH}$ in the rumen of cattle, rumen lactic acidosis (grain overload, grain poisoning, and acute indigestion) develops in sheep and cattle that have ingested large amounts of unaccustomed feeds rich in ruminally fermentable carbohydrates (Crichlow and Chaplin 1985; Nocek 1997).

The resulting production of large quantities of volatile fatty acids (VFA) and lactic acid decreases rumen $\mathrm{pH}$ to non-physiological levels, simultaneously weakening the buffering capacity of the rumen, and reduces the efficiency of rumen flora and fermentation. Lactic acidosis can cause ruminitis, metabolic acidosis, lameness, hepatic abscessation, pneumonia and death (Lean et al. 2000).

Indigestion also leads to hepatic disturbances (Padmaja and Rao, 2012), increase occurrences of leukocytosis (Stocker et al., 1999) and decrease milk yield in affected animals (Singh et al., 1996).

Acute ruminal acidosis is one of the - most dramatic forms of ruminal microbial fermentative disorders and in some cases is lethal in less than 24 hours (Gentile et al., 2004).

Sub-clinical ruminal acidosis is usually of greater economic importance than clinical disease and can often affect a significant proportion of the herd. Signs often associated with sub-clinical acidosis include a reduction in milk fat content, feed conversion efficiency, feed intake and decreased digestion of fiber (Lean et al., 2000), laminitis causing lameness (Nocek, 1997; Owens et al., 1998), liver abscessation (Owens et al., 1998), scouring (Nocek, 1997), and a higher incidence of left and right displacements of the abomasum (Shaver, 1997).

The most common ruminal disorders such as tympany, indigestion and impaction are characterized by poor appetite, altered $\mathrm{pH}$, reduced rumen motility and decreased microbial counts (Radostits et al., 2006).

Sudden change in the feed is the most common cause of indigestion in ruminants. Other factors such as feeding spoiled and moulded feeds, usingof antibiotics especially via oral route, sudden changes in climatic conditions also cause indigestion (Radostits et al., 2006).

Due to abrupt changes in feed, the ruminal microflora is unable to adapt resulting in indigestion. As rumen microflora plays an important role in ruminant digestion (Yokoyama and Johnson, 1998).

The aim of this study. The aim of this study is to evaluate the current knowledge of the pathophysiology of acidosis and alkalosis and provide practical information on the diagnosis, prevention and treatment of the condition in beef and dairy cattle.

\section{Materials and Methods}

\section{Location and date:}

Animals of the present work were belonged to different owners and private farms located at various areas around Monofia Governorate, Egypt. The work was done during the period from September 2016 to April 2017.

\section{Animals:}

A total number of thirty five adult native breed cattle one to three years old of both sexes were selected from field cases suffering from rumen dysfunction. The diseased Animals were clinically examined. Animals were divided on basis of ruminal $\mathrm{pH}$ and clinical signs into three groups. The number of diseased cases with Ruminal acidosis was 15(group I), simple indigestion twelve (group II) and those with Ruminal tympany eight (group III). In addition, five clinically adult caws were used as control (group IV).

\section{Samples:}

\subsection{Ruminal juice:}

About $50 \mathrm{ml}$ of ruminal juice was collected from each animal with the help of stomach tube and suction pump before and five days after therapy. The samples were transferred to the laboratory in a box containing dry ice for the immediate laboratory analysis. Samples were subjected to physical and microscopical examinations. 


\subsection{Blood samples:}

Blood samples were collected from the jugular vein aseptically for hematological analysis, in a sterile tube containing K3 Ethylene Diamine Tetra Acetic Acid (EDTA) before and five days after therapy. Hemoglobin ( $\mathrm{g} / \mathrm{dl})$, packed cell volume (percentage), total leukocyte count (x103/ $\mathrm{ml}$ ) and differential leukocyte count (percentage) were estimated as per the method described (FAO. 2010).

\section{Methods:-}

All animals were clinically examined according to Kelly, (1984). Physical examination of ruminal juice was conducted according to Coles, (1986). Total protozoa count in ruminal fluid samples was carried out according to Hungate, (1966). The differential count of rumen protozoa was done using the same slide of counting using high power lens (x40). Identification was carried out microscopically and depending upon the size of cell type, location of cilia, macro and micro nucleus, skeletal plates, caudal spines and projection of cuticle (Hungate, 1966 and Williams and Coleman, 1988).

The $\mathrm{pH}$ was measured immediately after collection by using $\mathrm{pH}$ meter (Dirksen and Smith 1987).

\section{Results}

\section{Ruminal acidosis (pH 4.6- 5.5):-}

The severity of clinical signs varied according to the degree of $\mathrm{pH}$ value of ruminal contents. Anorexia, dullness, depression, ruminal atony or complete stasis with slight tympany and congested mucous membranes in diseased cases. A splashing or tinkling sound was heard on rumen auscultation. Most cases showed yellowish white soft feces or diarrhea. The body temperature, heart, and respiratory rates ranged between $37.8-39.5 \mathrm{oC}, 79-115 / \mathrm{min}$., and 39-75/min. respectively.

\subsection{Simple indigestion ph ranged from slight acidosis. (5.5-6):-}

Diseased cases showed anorexia with yellowish green Soft feces or diarrhea without systemic changes. Slightly doughy ruminal contents on palpation, dull sound on ruminal percussion and Ruminal atony on auscultation were recorded. In appetence, emaciation and incomplete ruminal stasis were recorded in most diseased cow with low ruminal $\mathrm{PH}(5.5-6)$.

\subsection{Ruminal tympany pH (7.0 - 7.5):-}

The clinical signs reported in diseased cases were severe distension of the left side of abdomen at flank region with increase or complete cessation of ruminal motilities. Animals lied down and get up frequently as signs of discomfort. Most of diseased cases showed rapid respiration and heart rates (4572/min., and 76- 112/min respectively).

\section{Rumen analysis:-}

The obtained data of the studied parameters in Ruminal contents were presented in tables 1 .

\section{Blood analyses:-}

The obtained data of the studied blood parameters were presented in tables 1 .

The present clinical study was carried out to insure the therapeutic efficacy of different trials for ruminal disorders in cattle.

The results obtained are presented as follows.

Group I (severe acidosis), group II (moderate acidosis) and group III (tympany) had mean rumen fluid $\mathrm{pH}$ of $4.0 \pm 0.17,5.10 \pm 0.07$ and $7.50 \pm 0.07$ and respectively.

Ten apparently healthy cows served as healthy control for the comparative study. Clinical signs exhibited by severe acidotic goats (Group I) were the signs were observed anorexia, severe depression, sunken eyes, staggering gait, lameness, absence of rumination, ruminal motility absent, watery diarrhea, dehydration, oliguria to anuria, dyspnea, tachycardia, subnormal body temperature, sternal and lateral recumbency. Clinical signs after treatment in all acidotic cows disappeared.

The signs observed in simple indigestion cows (Group II) in-appetence, mild bloat, reduced rumen motility, reduced rumination, semisolid faeces, firm and doughy condition of rumen on palpation of left flank and dull sound on percussion of left flank. 
Table 1: Therapeutic efficacy of different regimens evaluated based on the comparative means of parameters as per ANOVA results.

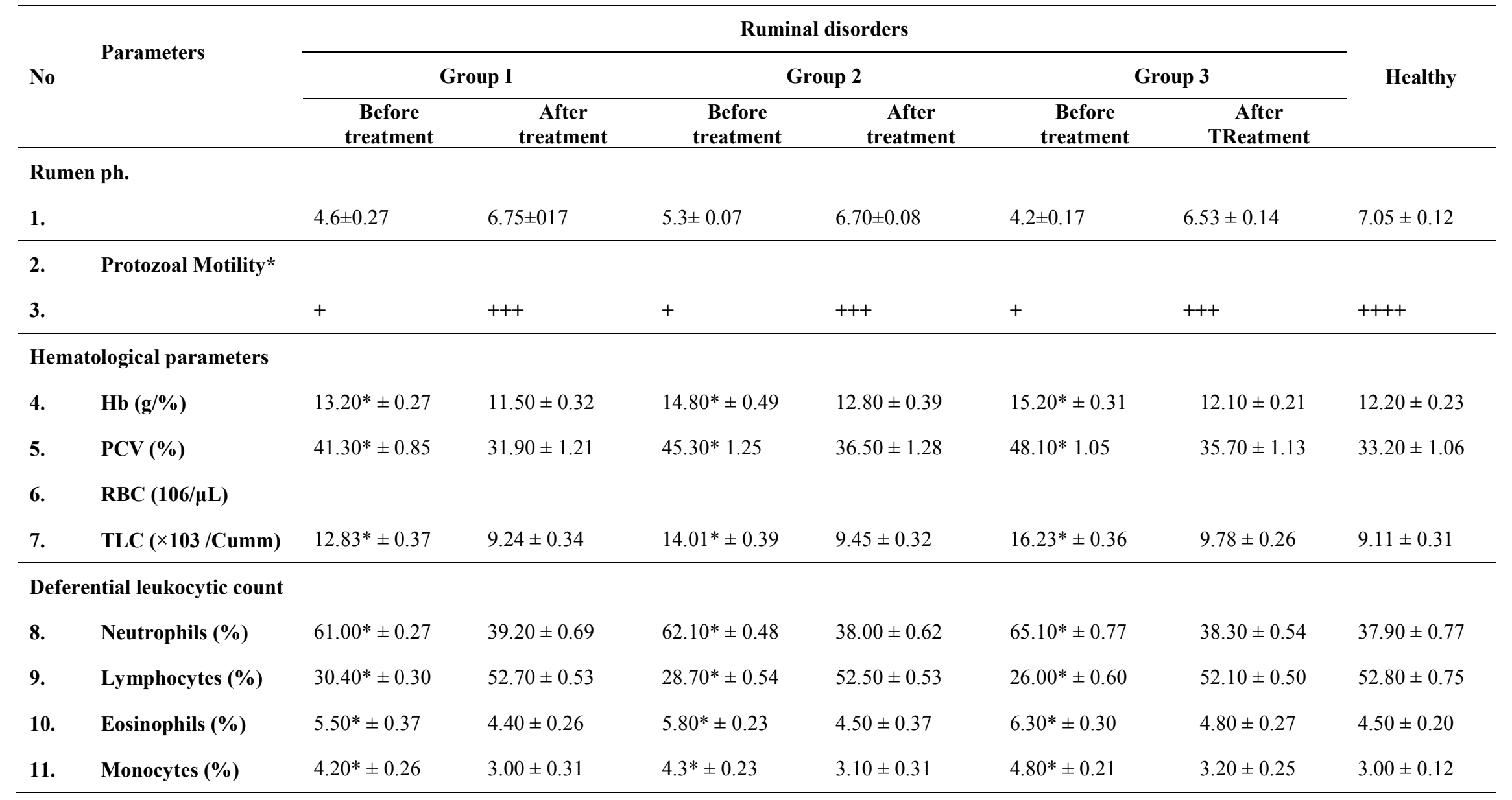


Whereas in tympany cows (Group III) the clinical signs reported in diseased cases were severe distension of the left side of abdomen at flank region with increase or complete cessation of ruminal motilities. Animals lied down and get up frequently as signs of discomfort.

The hematological parameters were studied before and after therapy in different group of ruminal disorders cow, The mean hemoglobin concentration in group I, II and III cows before and after treatment There was a significant increase $(p<0.05)$ in hemoglobin concentration of ruminal acidotic cows before treatment when compared to apparently healthy ones These values decreased among respective groups following therapy. Similarly, there was a no significant difference in hemoglobin concentration after treatment between group I, II, and III. The results are presented in table 1.

The mean PCV in cows belonging to group I, II and III before and after treatment. There was a significant increase $(p<0.05)$ in PCV count of group I, II and III cows before treatment when compared to apparently healthy (Group IV). These values decreased among respective groups following therapy. Similarly, there was a no significant difference in PCV after treatment between groups I, II and III. The results are presented in table 1 . The mean total leukocyte count in goats belonging to groups I, II and III before and after treatment are presented in table 1.

There was a significant increase $(p<0.05)$ in total leukocyte count of all affected cows before treatment when compared to apparently healthy cows (Group IV) .These values decreased among respective groups following therapy. Similarly, there was no significant difference in total leukocyte count following treatment between group I, II and III goats. The results are presented in table 1. The mean differential leukocyte count in group I, II and III goats before and after treatment revealed are presented in table 1.

Neutrophils, Lymphocytes, Eosinophils and Monocytesare presented in table 1. Neutrophils were significantly $(\mathrm{p}<0.05)$ increased in cows of group I, II, and III before treatment when compared to apparently healthy cows. This parameter decreased in group I, II, and III following 5 days therapy. Lymphocytes were significantly $(\mathrm{p}<0.05)$ decreased in group I, II, and III before treatment when compared to apparently healthy cows. These values increased in group I, II, and III following therapy by day 5 . Eosinophils were significantly $(p<0.05)$ increased in cows of groups I, II and III before treatment when compared to apparently healthy cows. These values decreased in group I, II and III after therapy. Monocytes were significantly altered in group I, II, and III before treatment when compared to apparently healthy cows. The values were decreased in group I, II and III which was not significant after therapy. The results are presented in table 1.

The therapeutic efficacy of the drugs used against various types of ruminal disorders in cows was assessed based on clinical improvement, resumed appetite, reduction in the degree of dehydration, and normal consistency of faeces. It was also assessed based on time taken for improvement in hematological parameters to reach near or normal. The various therapeutic treatments were continued for 5 successive days for all the cows in three groups. Group I (sever acidosis) and group II (moderate acidosis) cows were given sodium bicarbonates $1 \mathrm{~g} / \mathrm{kg}$ body weight, single dose orally daily for 5 days. With sodium bicarbonates $500 \mathrm{ml}$ iv, The ruminal disorders cows of group III (severe ruminal tympany) were administered simethicone (active charcoal) $250 \mathrm{ml}$ single dose orally daily for 3 days and ringer lactate $500 \mathrm{ml}$ for 5 days. The affected cows of all the three groups were administered same therapy Chlorphenarmine maleate $0.5 \mathrm{mg} / \mathrm{kg}$ body weight intramuscular, Tribivet $2 \mathrm{ml}$ intramuscular and Ringer's lactate $25 \mathrm{ml}, 50-75 \mathrm{ml}$ and $75-100 \mathrm{ml} / \mathrm{kg}$ body weight intravenously in group I, II and III respectively. The results are presented in table 1 .

Cows belonging to group I, II and III were observed during the therapy. Improvement in appetite, rumination and general condition parameters was noticed in group II and III next day after treatment. Whereas, the group I cows receiving Sodium bicarbonate had shown slow recovery in symptoms as compared to group II and III cows. Group III cows showed marked improvement in appetite, general condition and physical activity, along with absence of diarrhea after receiving and Sodium bicarbonate $1 \mathrm{~g} / \mathrm{kg}$ body weight orally. Improvement in clinical, ruminal fluid $\mathrm{pH}$, hematological parameters, their reversal to normally and overall clinical recovery was also evaluated after 5 days of treatment within and between groups.

\section{Discussion}

The present study was carried out for a period of 8 months from august 2017 to April 2018 among cows that were presented to the my privet Clinic, with a history of dietary abnormalities, accidental 
ingestion of carbohydrate rich diet and clinical manifestations of anorexia, distension of rumen, and diarrhea in cows, the digestive disorders.

Rumen dysfunctions are the most common problems to farmers. Ruminal acidosis occur in cows which gain access to large quantities of carbohydrates, particularly grain, Bread, bakery products, market and household waste. It is characterized by indigestion, toxemia, diarrhea, dehydration, rumen stasis, in coordination and sometimes death.

In the present study, clinical efficacy of routinely field subscribed therapy as Sodium bicarbonate and simethicone in the management of ruminal acidosis, and tympany was evaluated. Ruminal acidosis and tympany is an emergency disorder of fore-stomach which requires immediate treatment to prevent the death of the affected animals. Ruminal acidotic cows were treated according to the severity of the disease. The various therapy were continued for 5 successive days for all the cows in three groups. Group I (sever acidosis) cows received sodium bicarbonate $1 \mathrm{~g} / \mathrm{kg}$ body weight, single dose orally daily for 5 days. Where, group II (moderate acidosis) cows were given sodium bicarbonate $1 \mathrm{~g} / \mathrm{kg}$ body weight single dose orally daily for 5 days. Group III (ruminal tympany) were administered simethicone orally for 5 days. In addition, the affected cows of all the three groups were treated with Chlorphenarmine maleate $0.5 \mathrm{mg} / \mathrm{kg}$ body weight intramuscularly, Tribivet $2 \mathrm{ml}$ intramuscularly and Ringer's lactate $25 \mathrm{ml}, 50-75 \mathrm{ml}$ and $75-100 \mathrm{ml} / \mathrm{kg}$ body weight intravenously. IN group I, II and III respectively. Administration of oral Sodium bicarbonate neutralized the lactic acid produced locally inside the rumen to prevent chemical ruminitis and to restore normal ruminal $\mathrm{pH}$, which reduced the effect of metabolic / systemic acidosis. Similar treatment was advocated by many earlier researchers (Arora et al., 2011; Braun and Rihs 1992; Chakrabarti, 2006; Chaudhary et al., 2009, Choudhary et al., 2011). Sodium bicarbonate were used in the management of rumen acidosis in cows Chaudhary et al. (2009). A course of antihistaminic drug, Chlorphenarmine maleate was given to all the groups of goats to counteract histamine release due to chemical ruminitis and also reduce the rumen and blood histamine levels. Ringer's lactate fluid was given intravenousoly to correct the acidosis and dehydration and to restore renal function. It also maintains the sodium, potassium and chloride levels of acidotic cows. Intramuscular injection of Tribivet was administered to acidotic cows to correctthiamine deficiency caused by abnormal growth of thiaminase enzyme producing bacteria inside the rumen. Thiamine helps in metabolism of lactic acid and thus helps in preventing further systemic lactic acidosis.

Cowsin group I, II and III were observed during the therapy. Improvement in appetite, rumination and general condition was noticed in group I and II a day after treatment. GroupIIIcows which received simethicone hadshowed slow recovery in symptoms as compared to group I and II. The motility of rumen protozoa was vigorous $(+++)$, and the population was plenty $(+++)$ after treatment. The idophillic activity of the rumen protozoa was moderate type $(+++)$ which is in agreement with the finding of Shah et al. (2013). Group II cows showed marked improvement in appetite, general condition and physical activity, along with absence of diarrhea after receiving Sodium bicarbonate $1 \mathrm{~g} / \mathrm{kg}$ body weight orally. The therapeutic efficacy of the drugs used against various types of ruminal acidosis in cows was assessed based on clinical improvement, resumed appetite, reduction in the degree of dehydration, consistency of faeces normal, normal heart rate, respiration rate and conjunctival mucous membrane. Improvement in clinical, ruminal fluid, hematological parameters, their reversed to normally and total clinical recovery was observed after 5 th days of treatment within and between groups.

\section{Conclusion}

Farmers must be lessen to advisement of veterinarians to avoid loss in production and exposure of their animals to ruminal disorders and death, the diets, especially those supplemented with concentrates must contain effective fiber requirement. The animal must receive balanced diet to avoid acidosis, sub-clinical acidosis or tympany, to ensure that cows are receiving a diet that will keep rumen function optimal and safe.

\section{Reference}

Annison, E.F., and D. Lewis. 1959. Metabolism in the rumen. Cited by Choudhuri (1988).

Arora, N., N.A. Tufani, and T. Kumar, 2011. Grain overload in buffalo and its therapeutic management. Intaspolivet, 12:315-317. 
Bhaskar, V.V. and O.P. Galtam. 1976. Therapeutic evaluated of Himalayan batisa in cases of indigestlon in cattle and buffaloes. Pashudhan 24-25.

Blood, D.C. and V.P. Studdert, 1988. Comprehensive Veterinary Dictionary. London, Bailliere Tindall.

Braun, U., and T .Rihs, 1992. Schefer Ruminal lactic acidosis in sheep and goats. Vet. Record, 130:343349.

Chakrabarti, A., 2006. Text Book of Clinical Veterinary Medicine 3rd revised and enlarged edition. Kalyani Publishers, New Dehli., 291-295.

Chaudhary, P., J. Varshney, V. Deshmukh, and S. Desai, 2009. Bufzone for the management of bovine acidosis. Intas Polivet., 10(1):8-12.

Choudhary, S., A. Muralidhara, and B.M. Ravindranath, 2011. Ruminal acidosis in small ruminants and its therapeutic management. IntasPolivet., 12(2):320.

Coles, E.H., 1986. Veterinary Clinical Pathology. $4^{\text {th }}$ ed., W.B. Saunders company, Philadelphia, U.S.A.

Crichlow, E.C. and R.K. Chaplin, 1985. Ruminal lactic acidosis: Relationship of forestomach motility to nondissociated volatile fatty acids levels. American Journal of Veterinary Research, 46(9): 1908-1911.

Dirksen, V.G. and M.C. Smith, 1987. Acquisition and analysis of bovine rumen fluid. Bovine Practitioner, 2:108-116.

FAO, Food and Agricultural Organisation, 2010. Livestock Population and Production Statistics, United Nation, Rome.

Gentile A, Sconza S, Lorenz I, et al. D-Lactic Acidosis in Calves as a Consequence of Experimentally Induced Ruminal Acidosis. Journal of Veterinary Medicine Series A 2004; 51:64-70.hofiund,S . 1951. Cited by Thirunarayanan -et -al. (1985).

Hofiund, S . 1951. Cited by Thirunarayanan et al. (1985).

Hungate, R.E., 1966. The Rumen and its Microbes. 1st Ed,Acadamic Press, New York. U.S.A.

Kimberlin, C.V., 1988. Jensen and Swiff's disease of sheep. 3rd ed., Lea and febiger. Philadelphia, U.S.A.

Lean, I.J., L.K. Wade, et al., 2000. New Approaches to Control of Ruminal Acidosis in Dairy Cattle. Asian-Australasian Journal of Animal Sciences 13 (Suppl): 266-269.

Misra, S.K. and R.C. Tripathy, 1963. S'tudies on the rumrn liquor from cattle fed exclusively on paddy straw. Indian Vet. J. 40 : 496-501.

Nichols, R.E., 1957. Practical measurement of pH of rumen fluid. J. Am., Vet., Med. Asso., 131: 107108.

Nocek, J.E., 1997. Bovine Acidosis: Implications on Laminitis. Journal of Dairy Science 80(5): 10051028.

Owens, F.N., D.S. Secrist, et al., 1998. Acidosis in Cattle: A Review. Journal of Animal Science 76: 275-286.

Padmaja, K. and D.S.T. Rao, 2012. Biochemical and therapeutic studies on post-parturient indigestion (PPI) with particular reference to hepatic insufficiency in buffaloes. Inter. J. Pharma Biosci., 3: 40-45.

Radostits, O.M., C.C. Gay, K.W. Hinchcliff and P.D. Constable. Ed., 2006. Veterinary Medicine: A textbook of cattle, horses, sheep, pigs and goats, 10th Edition, Saunders Publishers.

Radostits, O.M., C.D. Blood, and C.C. Gay, 2000. Veterinary Medicine. $9^{\text {th }}$ ed., Bailliere, Tindall, London.

Shah, O., M. Shaheen, G. Gupta, A. Lather, S.U. Nabi, A.R. Wani, and M. Hassan, 2013. Clinical and haematobiochemical changes in alkaline indigestion in Southdown breed of sheep in Kashmir valley. Haryana Vet., 52: 63-65.

Shaver, R.D., 1997. Nutritional Risk Factors in the Aetiology of Left Displaced Abomasum in Dairy Cows: A Review. Journal of Dairy Science, 80: 2449-2453.

Singh, N., M.A. Akbar, R. Kumari and B.M. Khanna, 1996. Effect of some treatment on ruminal environment and milk production in clinical cases of indigestion in buffaloes. Ind. Vet. Med. J., 20: $115-118$.

Stocker, H., H. Lutz, and P. Rusch, 1999. Clinical, haematological and biochemical findings in milkfed calves with chronic indigestion. Vet. Rec., 145: 307-311. U.S.A. 
Vanitha, V., A.P. Nambi, B. Gowri, and S. Kavitha, 2010. Rumen impaction in cattle with indigestible foreign bodies in Chennai, 6: 138-140.

Williams, L. and Coleman, 1988. The rumen protozoa in Hobson edition, Rumen microbial Ecosystem. 77-128, Elsevier Applied Sciences,

Yokoyama, M.T., and K.A. Johnson, 1998. The ruminant animal: Digestive physiology and nutrition, D.C. Church ed. Prentice Hall., 125. 